\title{
Thoracic pedicle screw fixation for spinal deformity
}

\author{
Michael K. Rosner, M.D., David W. Polly, JR., M.D., Timothy R. KuKlo, M.D., \\ AND STEPHEN L. ONDRA, M.D.
}

Department of Orthopaedic Surgery and Rehabilitation, Neurosurgery Service, Walter Reed Army Medical Center, Washington, DC; Department of Surgery, Uniformed Services University of the Health Sciences, Bethesda, Maryland; and Department of Neurological Surgery, Northwestern University Medical School, Chicago, Illinois

\begin{abstract}
Techniques to improve segmental fixation have advanced the ability to correct complex spinal deformity. The purpose of instrumentation is to correct spinal deformity or to stabilize the spine to enhance the long-term biological fusion. The ultimate goal of spinal deformity surgery is the creation of a stable, balanced, pain-free spine centered over the pelvis in the coronal and sagittal planes. The minimum number of segments should be fused. These concepts remain challenging in the setting of deformity and instability. Successful results can be obtained if the surgeon understands the technology available, its capabilities, biological limitations, and the desired solution.

The authors prefer to use thoracic pedicle screws when treating patients with spinal deformity because they provide greater corrective forces for realignment. This allows shorter-segment constructs and the possibility of true derotation in correction. In this article the authors focus on the use of thoracic transpedicular screw fixation in the management of complex spinal disorders and deformity.
\end{abstract}

KEY WORDS - spinal stabilization - biomechanics • spinal deformity

The purpose of instrumentation is to correct spinal deformity or to stabilize the spine to enhance long-term biological fusion. The ultimate goal of spinal deformity surgery is to create a stable, balanced, pain-free spine centered over the pelvis in the coronal and sagittal planes. The minimum number of segments should be fused. These concepts remain challenging in the setting of deformity and instability. The surgeon can obtain successful results by understanding the technology available, its capabilities, biological limitations, and the desired solution. We have come to prefer the use of thoracic pedicle screws when treating patients with complex spinal deformity. In this article we focus on the use of transpedicular screw fixation in the management of spinal deformity.

\section{THORACIC PEDICLE SCREW FIXATION}

Transpedicular screw fixation has become an increasingly popular procedure in the treatment of not only spinal deformity but also degenerative disease, trauma, and tumors. Earlier fixation methods typically involved the use of hooks and wires. Pedicle screw-assisted instrumentation, however, provides more rigid fixation. . $^{411,15,23,24,31,44}$ An understanding of pedicle screw biomechanics, bone quality, pedicle morphometry, complications, and salvage options is required when placing pedicle screw constructs.

Pedicle screws allow fixation of the implant to all three columns of the spine. The addition of internal fixation serves the dual function of improving arthrodesis by rigid immobilization of the instrumented segments and correcting preexisting deformities by allowing application of greater corrective forces. As noted previously, prior fixation methods involved the use of hooks and wires, which are inferior bone anchors compared with pedicle screws. ${ }^{4,11,12,15,23,24,31,41,44}$ The screw-bone interface is generally stronger than the hook-bone and wire-bone interface. Often, this permits the use of a shorter construct, thus avoiding adjacent segments. Another advantage is the fact that the posterior elements do not need to be intact (Fig. 1).

A thorough knowledge of pedicle anatomy and orientation is integral to the safe application of pedicle screw instrumentation. Numerous factors affect the safety and accuracy of thoracic transpedicular screw fixation in patients with complex spinal deformities. The variable biplanar segmental angulations of the pedicle are unique in deformity surgery. The eccentric, concave-side displacement of the spinal cord in patients with scoliosis also changes the risk of medially positioned screws. The pedicle morphometry of the concave pedicle is often smaller or narrowed. ${ }^{26,27}$ Preoperative assessment to determine Cobb angles, vertebral rotation, and curvature becomes even more important.

Debate continues regarding the incidence, degree, and 


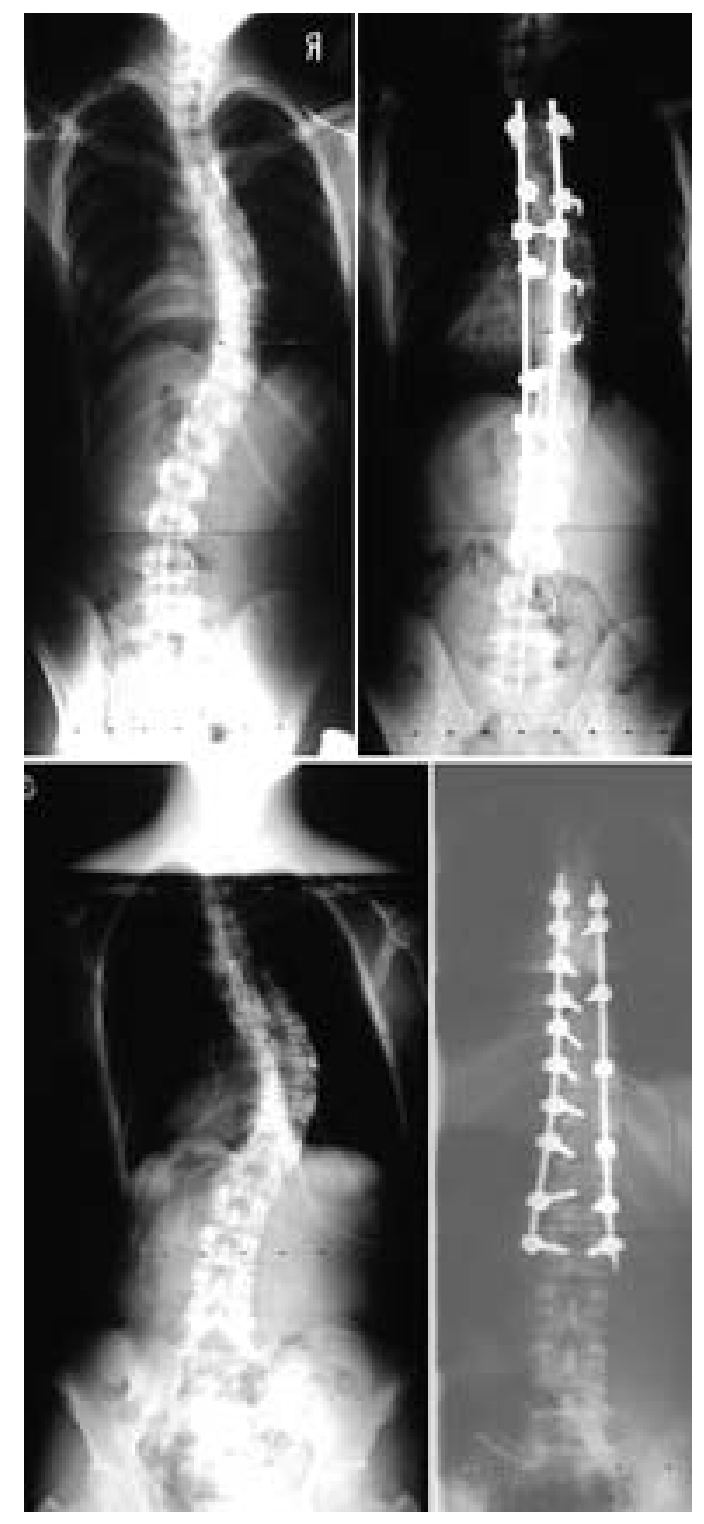

Fig. 1. Radiographic studies obtained in patients with similar deformities. Preoperative (upper left) and postoperative (upper right) radiographs of a case involving hook and rod instrumentation. Preoperative (lower left) and postoperative (lower right) radiographs of a case involving pedicle screw correction. Screws save levels and give better curve correction.

potential neurological sequelae of screw penetration through the medial pedicle wall. Much of the initial thought was extrapolated from studies involving treatment of the lumbar spine. The sequelae of medial wall violations are well documented in cadaveric models. ${ }^{34,35}$ In relation to the increasing use of thoracic transpedicular screw fixation during the last decade, there have been reports on the accuracy of screw placement. The initial accuracy in cadavers ranged from 45 to $85 \%$ for conventional insertion techniques. ${ }^{5,9,35,42,43}$ In these studies screw diameter, insertion technique, and entry points varied. Computer-assisted surgery ${ }^{19}$ and fluoroscopically assisted laser targeting ${ }^{29}$ rates were 81 and $99 \%$, respectively. Mul- tiple case series have now been reported. Gertzbein and Robbins ${ }^{14}$ reported a $26 \%$ incidence of medial cortical penetration of up to $8 \mathrm{~mm}$ with only two minor neurological injuries in patients without coronal deformity. In their study Belmont, et al., ${ }^{1}$ placed 279 screws in the thoracic spine (T1-12) in their patients. The overall fully contained accuracy rate was $57 \%$, with 120 screws penetrating either the medial (14\% [range 1-4 mm]) or lateral (29\%) cortex. Other authors have documented a safe experience with thoracic pedicle screws in patients with coronal-plane deformities. ${ }^{2,6,12,16,32,33}$ Belmont, et al., ${ }^{2}$ specifically compared the accuracy and safety of thoracic pedicle screw fixation in patients with and without coronal-plane deformities. They reported an overall rate of acceptably positioned screws of $98 \%$ in patients with coronal-plane deformity and $99 \%$ in those without such deformity. The authors also elucidated the concept of "acceptable" compared with "fully contained" screw placement. Acceptable screw placement included generous lateral cortex violation $(<6 \mathrm{~mm})$ and minor medial cortex breech $(<2 \mathrm{~mm})$.

Two trajectories are also used when placing thoracic pedicle screws. Although the anatomical trajectory has a longer bone channel and allows for a longer screw to be placed, it mandates the use of a multiaxial screw to connect it to the rod. The straight-forward trajectory allows for fixed-head screws and true direct vertebral derotation (Fig. 2). In addition to the aforementioned trajectories, alternative screw placement options exist other than entering the pedicle directly. One such insertion method is the in-out-in technique, which involves a more lateral insertion point and oblique trajectory. Although the technique allows for a more lateral insertion, by virtue of its steeper angulation, it results in the screw being directed toward the spinal canal. ${ }^{22} \mathrm{O}$ 'Brien, and colleagues $(\mathrm{O}$ 'Brien $\mathrm{MF}$, Wood J, Lowe TG: Thoracic pedicle vs pedicle/rib screw fixation: 35th Annual Meeting of the Scoliosis Research Society. Cairns, Australia, 2000) compared this technique with standard insertion techniques and used a loading rate of $50 \mathrm{~N} / \mathrm{second}$ to generate load-displacement data, yield strength, and maximum load to failure. They found that there is relatively good fixation strength associated with the pedicle-rib technique compared with standard thoracic screw fixation and that it resulted in achieving approximately $70 \%$ of the biomechanical fixation strength for the latter.

The hardware involved in posterior pedicle screw fixation is considered safe and effective for stabilizing a spinal motion segment. There are, however, several rare but significant complications that may occur with anterior or lateral cortical breach. In contrast to the well-described vascular and visceral complications associated with anterior thoracic instrumentation, there are few series in which authors have described recurrent complications of misplaced screws when placing posterior thoracic instrumentation. There are case reports involving the misplacement of thoracic pedicle screws and subsequent complications. Vanichkachorn, et al. ${ }^{36}$ described the removal of a broken $\mathrm{T}-12$ pedicle screw that had subsequently migrated into the retroperitoneal space, necessitating anterior exposure; no vascular or further visceral insult occurred. Heini, et al. ${ }^{18}$ described a fatal complication that occurred when a a Kirschner wire injured the right coronary artery during a 


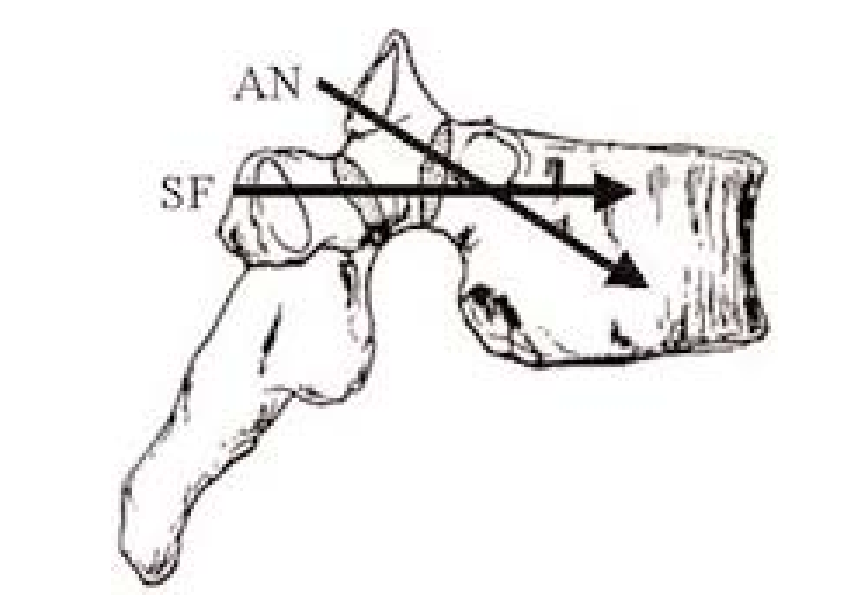

Fig. 2. Two thoracic pedicle screw trajectories are currently popular. The straight-forward (SF) technique is a slightly modified Roy-Camille technique as popularized by Suk and Lenke. The anatomical technique (AN) was initially popularized by Harms and advocated by Polly. The straight-forward approach has better biomechanical performance parameters. The anatomical technique has the largest possible bone channel for screw placement.

procedure to implant thoracic pedicle instrumentation. Liljenqvist, et al., ${ }^{25}$ placed 120 thoracic pedicle screws in 32 consecutively treated patients with idiopathic scoliosis and noted $30(25 \%)$ of the screws penetrated the pedicle cortex or the vertebral body anterior cortex. Three screws penetrated the anterior vertebral cortex and one of the screws was replaced because of direct proximity to the thoracic aorta. ${ }^{25}$

Long-segment construct-related biomechanics involve a complex three-dimensional concept, which has been simplified to be modeled in separate planes. White and Panjabi ${ }^{38}$ and White, et al. ${ }^{39}$ have been credited with establishing the usefulness of analyzing spinal biomechanics in the coronal and sagittal planes by using axial and transverse forces. The third dimension, one of rotation and translation, has been well examined by Wood and colleagues ${ }^{40}$ who demonstrated a variable pattern of involvement with scoliotic curve involvement. Spinal instrumentation-induced deformity correction results from complex bending moments produced by distraction and compression forces involving the various longitudinal and attachment members. ${ }^{37}$

Traditionally short-segment constructs were considered to be those implanted one level above and one level below a fracture; long-segment constructs involved Harrington rod instrumentation that, in fractures, was typically applied three levels above and two below. The biomechanics of long-segment fixation involve a number of factors that affect the overall construct performance. Choma, et al., ${ }^{8}$ have shown that simply the direction of the hooks affects rod strain. Rod strain is maximal at the apex of the deformity, and stress concentration occurs with claw configurations as opposed to hooks directed toward the apex, such as in Harrington compression rod type of pattern.

Initially, Shufflebarger and Clark ${ }^{30}$ popularized the concept of smaller-diameter flexible rod fixation involving a greater number of hook attachment sites. The biomechanical basis for this concept was subsequently established by Orchowski, et al., ${ }^{28}$ who demonstrated that the number of hooks had a greater influence on percentage increase in stiffness than did a relative increase in rod diameter. They also showed that sagittal contour had a profound effect on overall construct behavior and that this far outweighed the increase of stiffness achieved by either hook number or rod diameter. This concept of the primacy of the effect of

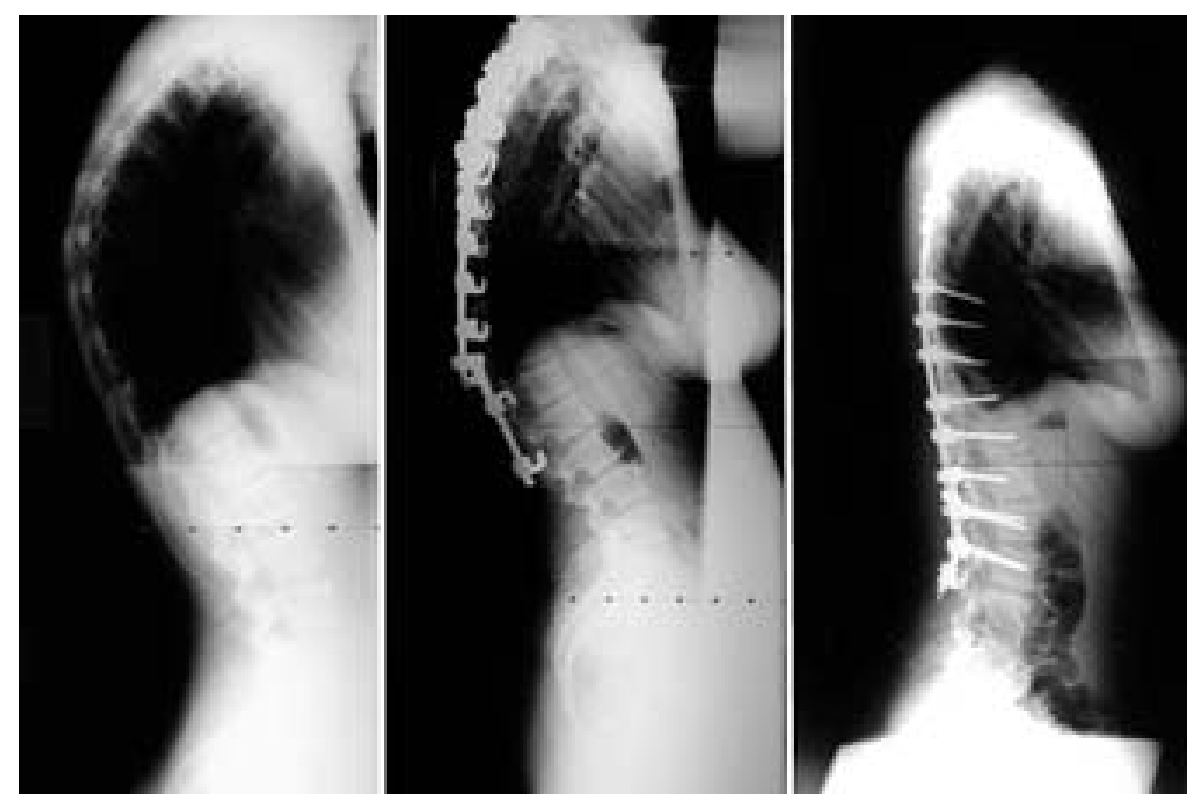

Fig. 3. Radiographs. In this case, a sagittal-plane deformity was previously instrumented; however, loss of correction occurred. The patient was then referred and underwent multiple posterior osteotomies, segmental fixation, and deformity correction, which was primarily achieved at the thoracolumbar junction and through the segments instrumented with pedicle screws. 


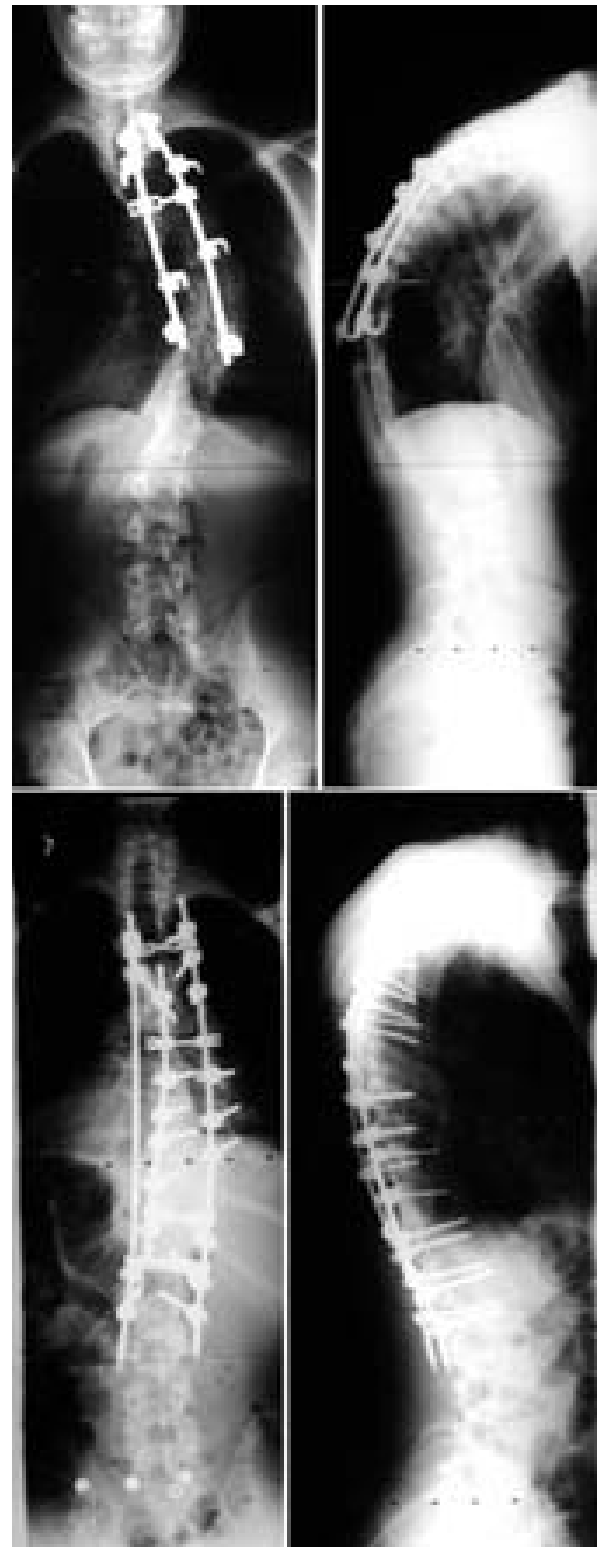

Fig. 4. Radiographs. In this case, residual coronal- and sagittalplane deformity was present after multiple previous osteotomies. The patient underwent multiple apical posterior osteotomies, segmental pedicle screw fixation, and coronal and sagittal balance improvement was demonstrated postoperatively.

sagittal contour was confirmed by Belmont, et al., ${ }^{3}$ who assessed kyphosis-type constructs.

Again, the findings of Choma, et al., ${ }^{8}$ were confirmed, showing that apically directed hook patterns decreased rod strain compared with the claw configurations. Preliminary assessment of all screw constructs has provided limited evidence specifying the number of screws necessary to achieve optimal construct rigidity. Contrary to the intuitive concept that bilateral placement of screws at every level would create greater stiffness, Belmont, et al., ${ }^{1,2}$ have reported that there appears to be a threshold of four to six end screws, which is consistent with the findings of Kostuik, et al., ${ }^{20}$ after which the pattern of screw

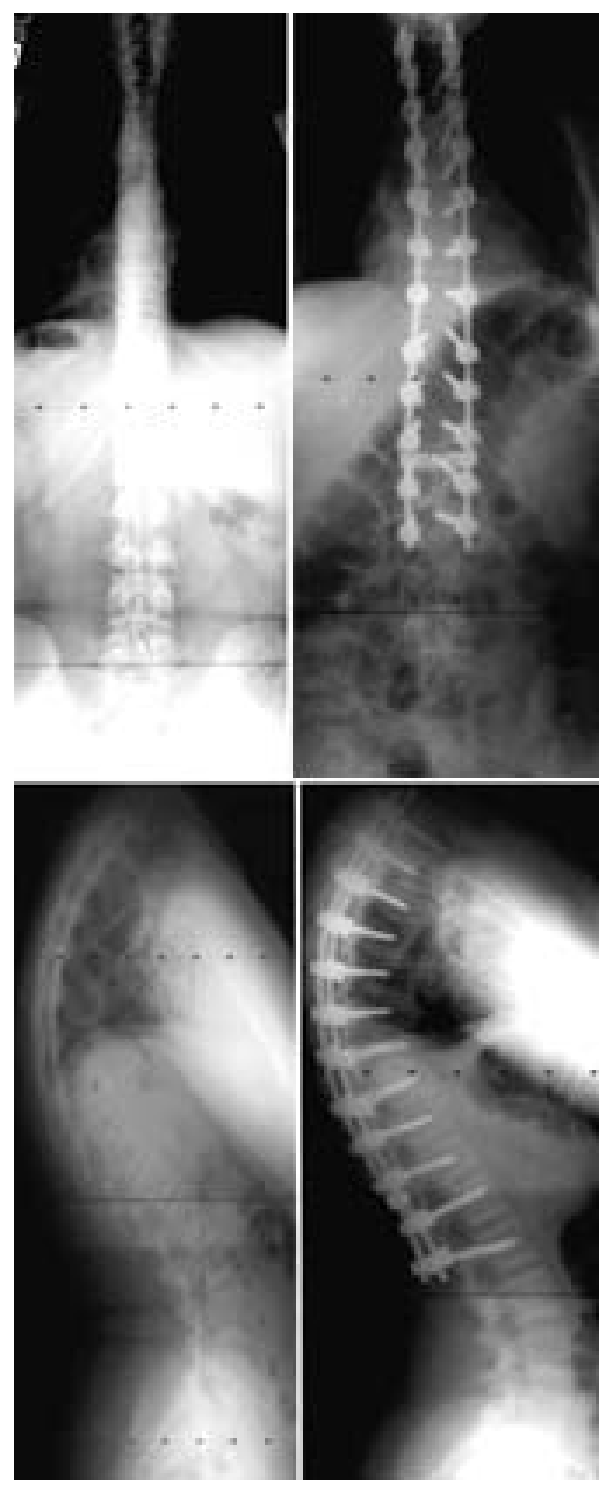

Fig. 5. Radiographs. In this case, Scheuermann kyphosis $\left(96^{\circ}\right)$ was corrected via a posterior-only approach in which multilevel Smith-Petersen osteotomies and segmental pedicle screw fixation were performed.

placement in the intervening segments appears to be less critical for overall construct performance. The exact explanation of this remains unclear.

Overall testing of construct stiffness is only one measure of the need for different anchor types. The concept of deformity correction mechanics is also critical in the selection of anchor points. Harrington's initial mechanism of deformity correction was coronal-plane distraction, which was very effective at correcting coronal abnormalities but induced secondary sagittal-plane abnormalities. When posterior to the instantaneous axis of rotation, distraction induces kyphosis and compression induces lordosis. Typically, Harrington distraction instrumentation extending distally into the lower lumbar spine resulted in flat back syndrome or positive sagittal imbalance. ${ }^{21}$ Compression instrumentation, such as the Harrington compression 
rod, is a very effective tool when applied posteriorly in combination with Smith-Petersen osteotomies to correct kyphotic deformities.

Cotrel and Dubousset ${ }^{10}$ demonstrated the derotation maneuver for correction of coronal abnormalities. Initially it was believed that this maneuver translated scoliosis into kyphosis. Wood, et al., ${ }^{40}$ subsequently demonstrated that the result of this derotation maneuver was merely a lateral translation and not a true derotation. It is unclear if segmental thoracic screws allow true derotation, but this may be the case. The benefits of thoracic screws were further assessed by Wood and colleagues ${ }^{41}$ who demonstrated that pedicle screws increased torsional stiffness when placed at the distal ends of the constructs implanted for deformity correction. Chiba, et al., ${ }^{7}$ also demonstrated the advantage of increased stiffness when using pedicle screws in hybrid constructs of short-segment fusions. In treating their patients with pedicle screws Hamill, et al. ${ }^{17}$ also demonstrated improved correction and fewer levels fused in the thoracolumbar spine during scoliosis correction.

Suk and coworkers ${ }^{32}$ reported the use of all-screw constructs in which a screw was inserted at every level, typically on the concavity of the curve. They found that true derotation was possible when placing the all-screw construct and a rigid rod. When a screw was inserted at every level, the mean correction was $72 \%$, whereas when using the Cotrel-Dubousset hood construct correction with the screws placed in a hook pattern, correction was $55 \%$. Their efforts have reconfirmed the importance of segmental fixation in which there is an attachment point at each vertebra to achieve control (Fig. 3). Currently, these authors advocate a direct vertebral derotation maneuver and the use of screws to create additional improvement in deformity correction.

\section{CONCLUSIONS}

The purpose of instrumentation is to correct spinal deformity or to stabilize the spine to enhance the biological fusion (Fig. 4). Thoracic pedicle screws are another tool for spine surgeons with which they can address spinal disease and fuse the minimum number of segments possible (Fig. 5). Surgeons can obtain successful results by understanding the technology available, the biological limitations, and the desired solution. We have come to perfer the use of thoracic pedicle screws when managing complex spinal disorders and deformity with the goal of providing a stable, balanced, pain-free spine centered over the pelvis. Thoracic pedicle screw placement is demanding but has proven to be possible. Understanding longsegment biomechanics allows optimal construct design. Thoracic pedicle screws as anchor points yield better correction and may well lead to better clinical outcomes.

\section{References}

1. Belmont PJ Jr, Klemme WR, Dhawan A, et al: In vivo accuracy of thoracic pedicle screws. Spine 26:2340-2346, 2001

2. Belmont PJ Jr, Klemme WR, Robinson M, et al: Accuracy of thoracic pedicle screws in patients with and without coronal plane spinal deformities. Spine 27:1558-1566, 2002

3. Belmont PJ Jr, Polly DW Jr, Cunningham BW, et al: The effects of hook pattern and kyphotic angulation on mechanical strength and apical rod strain in a long-segment posterior construct using a synthetic model. Spine 26:627-635, 2001

4. Berlemann U, Cripton PA, Rincon L, et al: Pull-out strength of pedicle hooks with fixation screws: influence of screw length and angulation. Eur Spine J 5:71-73, 1996

5. Berlet GC, Boubez G, Gurr KR, et al: The USS pedicle hook system: a morphometric analysis of its safety in the thoracic spine. Universal Spine System. J Spinal Disord 12:234-239, 1999

6. Brown CA, Lenke LG, Bridwell KH, et al: Complications of pediatric thoracolumbar and lumbar pedicle screws. Spine 23: 1566-1571, 1998

7. Chiba M, McLain RF, Yerby SA, et al: Short-segment pedicle instrumentation. Biomechanical analysis of supplemental hook fixation. Spine 21:288-294, 1996

8. Choma TJ, Chwirut D, Polly DW Jr: Biomechanics of long segment fixation: hook patterns and rod strain. J Spinal Disord 14:125-132, 2001

9. Cinotti G, Gumina S, Ripani M, et al: Pedicle instrumentation in the thoracic spine. A morphometric and cadaveric study for placement of screws. Spine 24:114-119, 1999

10. Cotrel Y, Dubousset J, Guillaumat M: New universal instrumentation in spinal surgery. Clin Orthop 227:10-23, 1988

11. Cunningham BW, Sefter JC, Shono Y, et al: Static and cyclical biomechanical analysis of pedicle screw spinal constructs. Spine 18:1677-1688, 1993

12. Delorme S, Labelle H, Aubin CE, et al: A three-dimensional radiographic comparison of Cotrel-Dubousset and Colorado instrumentations for the correction of idiopathic scoliosis. Spine 25:205-210, 2000

13. Gayet LE, Pries P, Hamcha H, et al: Biomechanical study and digital modeling of traction resistance in posterior thoracic implants. Spine 27:707-714, 2002

14. Gertzbein SD, Robbins SE: Accuracy of pedicular screw placement in vivo. Spine 15:11-14, 1990

15. Gurr KR, McAfee PC, Shih CM: Biomechanical analysis of anterior and posterior instrumentation systems after corpectomy. A calf-spine model. J Bone Joint Surg Am 70: 1182-1191, 1988

16. Halm H, Niemeyer T, Link T, et al: Segmental pedicle screw instrumentation in idiopathic thoracolumbar and lumbar scoliosis. Eur Spine J 9:191-197, 2000

17. Hamill CL, Lenke LG, Bridwell KH, et al: The use of pedicle screw fixation to improve correction in the lumbar spine of patients with idiopathic scoliosis. Is it warranted? Spine 21: 1241-1249, 1996

18. Heini P, Scholl E, Wyler D, et al: Fatal cardiac tamponade associated with posterior spinal instrumentation. A case report. Spine 23:2226-2230, 1998

19. Kim KD, Johnson JP, Bloch O, et al: Computer-assisted thoracic pedicle screw placement: an in vitro feasibility study. Spine 26:360-364, 2001

20. Kostuik JP, Munting E, Valdevit A: Biomechanical analysis of screw load sharing in pedicle fixation of the lumbar spine. $\mathbf{J}$ Spinal Disord 7:394-401, 1994

21. Lagrone MO, Bradford DS, Moe JH, et al: Treatment of symptomatic flatback after spinal fusion. J Bone Joint Surg Am 70:569-580, 1988

22. Lehman RA Jr, Kuklo TR, O'Brien MF: Biomechanics of thoracic pedicle screw fixation. Part I: Screw biomechanics. Seminars in Spine Surgery 14:8-15, 2002

23. Liljenqvist U, Hackenberg L, Link T, et al: Pullout strength of pedicle screws versus pedicle and laminar hooks in the thoracic spine. Acta Orthop Belg 67:157-163, 2001

24. Liljenqvist U, Lepsien U, Hackenberg L, et al: Comparative analysis of pedicle screw and hook instrumentation in posterior correction and fusion of idiopathic thoracic scoliosis. Eur Spine J 11:336-343, 2002

25. Liljenqvist UR, Halm HF, Link TM: Pedicle screw instrumen- 
tation of the thoracic spine in idiopathic scoliosis. Spine 22: 2239-2245, 1997

26. Liljenqvist UR, Link TM, Halm HF: Morphometric analysis of thoracic and lumbar vertebrae in idiopathic scoliosis. Spine 25:1247-1253, 2000

27. O'Brien MF, Lenke LG, Mardjetko S, et al: Pedicle morphology in thoracic adolescent idiopathic scoliosis: is pedicle fixation an anatomically viable technique? Spine 25:2285-2293, 2000

28. Orchowski J, Polly DW Jr, Klemme WR, et al: The effect of kyphosis on the mechanical strength of a long-segment posterior construct using a synthetic model. Spine 25:1644-1648, 2000

29. Schwend RM, Dewire PJ, Kowalski TM: Accuracy of fluoroscopically assisted laser targeting of the cadaveric thoracic and lumbar spine to place transpedicular screws. J Spinal Disord 13:412-418, 2000

30. Shufflebarger HL, Clark CE: Cotrel-Dubousset instrumentation. Orthopedics 11:1435-1440, 1988

31. Skinner R, Maybee J, Transfeldt E, et al: Experimental pullout testing and comparison of variables in transpedicular screw fixation. A biomechanical study. Spine 15:195-201, 1990

32. Suk SI, Lee CK, Kim WJ, et al: Segmental pedicle screw fixation in the treatment of thoracic idiopathic scoliosis. Spine 20: 1399-1405, 1995

33. Suk SI, Lee CK, Min HJ, et al: Comparison of Cotrel-Dubousset pedicle screws and hooks in the treatment of idiopathic scoliosis. Int Orthop 18:341-346, 1994

34. Vaccaro AR, Rizzolo SJ, Allardyce TJ, et al: Placement of pedicle screws in the thoracic spine. Part I: Morphometric analysis of the thoracic vertebrae. J Bone Joint Surg Am 77: 1193-1199, 1995

35. Vaccaro AR, Rizzolo SJ, Balderston RA, et al: Placement of pedicle screws in the thoracic spine. Part II: An anatomical and radiographic assessment. J Bone Joint Surg Am 77: 1200-1206, 1995

36. Vanichkachorn JS, Vaccaro AR, Cohen MJ, et al: Potential large vessel injury during thoracolumbar pedicle screw removal. A case report. Spine 22:110-113, 1997
37. White AA III, Panjabi MM: Biomechanical considerations in surgical management of the spine, in White AA III, Panjabi MM (eds): Clinical Biomechanics of the Spine. Philadelphia: JB Lippincott, 1990, pp 511-634

38. White AA III, Panjabi MM: The clinical biomechanics of scoliosis. Clin Orthop 118:100-112, 1976

39. White AA III, Panjabi MM, Thomas CL: The clinical biomechanics of kyphotic deformities. Clin Orthop 128:8-17, 1977

40. Wood KB, Transfeldt EE, Ogilvie JW, et al: Rotational changes of the vertebral-pelvic axis following Cotrel-Dubousset instrumentation. Spine 16 (Suppl 8):404-408, 1991

41. Wood KB, Wentorf FA, Ogilvie JW, et al: Torsional rigidity of scoliosis constructs. Spine 25:1893-1898, 2000

42. Xu R, Ebraheim NA, Ou Y, et al: Anatomic considerations of pedicle screw placement in the thoracic spine. Roy-Camille technique versus open-lamina technique. Spine 23:1065-1068, 1998

43. Xu R, Ebraheim NA, Shepherd ME, et al: Thoracic pedicle screw placement guided by computed tomographic measurements. J Spinal Disord 12:222-226, 1999

44. Zdeblick TA, Kunz DN, Cooke ME, et al: Pedicle screw pullout strength. Correlation with insertional torque. Spine 18: 1673-1676, 1993.

Manuscript received November 21, 2002.

Accepted in final form December 21, 2002.

The opinions or assertions contained herein are the private views of the authors and are not to be construed as official or as reflecting the views of the US Army or the Department of Defense. The authors are employees of the US government. This work was prepared as part of their official duties, and, as such, there is no copyright to be transferred.

Address reprint requests to: Stephen L. Ondra, M.D., Department of Neurological Surgery, Northwestern University Medical School, 233 East Erie, Suite 614, Chicago, Illinois 60611. email: Sondra@nmff.org. 